Article

\title{
Fatigue Properties of the Ultra-High Strength Steel TM210A
}

\author{
Guang-qiang Yin ${ }^{1,2}$ (D), Xia Kang ${ }^{1}$ and Gui-ping Zhao ${ }^{1, *}$ \\ 1 State Key Laboratory for Strength and Vibration of Mechanical Structures, School of Aerospace, \\ Xi'an Jiaotong University, Xi'an 710049, China; guangqiang12345@163.com (G.-q.Y.); \\ 18200288310@163.com (X.K.) \\ 2 Institute of Aviation Equipment, Qing'an Group Corporation Limited, Xi'an 710077, China \\ * Correspondence: zhaogp@xjtu.edu.cn; Tel.: +86-029-8266-5439
}

Received: 26 July 2017; Accepted: 6 September 2017; Published: 9 September 2017

\begin{abstract}
This paper presents the results of an experiment to investigate the high cycle fatigue properties of the ultra-high strength steel TM210A. A constant amplitude rotating bending fatigue experiment was performed at room temperature at stress ratio $\mathrm{R}=-1$. In order to evaluate the notch effect, the fatigue experiment was carried out upon two sets of specimens, smooth and notched, respectively. In the experiment, the rotating bending fatigue life was tested using the group method, and the rotating bending fatigue limit was tested using the staircase method at $1 \times 10^{7}$ cycles. A double weighted least square method was then used to fit the stress-life (S-N) curve. The S-N curves of the two sets of specimens were obtained and the morphologies of the fractures of the two sets of specimens were observed with scanning electron microscopy (SEM). The results showed that the fatigue limit of the smooth specimen for rotating bending fatigue was $615 \mathrm{MPa}$; the ratio of the fatigue limit to tensile strength was 0.29 , and the cracks initiated at the surface of the smooth specimen; while the fatigue limit of the notched specimen for rotating bending fatigue was $363 \mathrm{MPa}$, and the cracks initiated at the edge of the notch. The fatigue notch sensitivity index of the ultra-high strength maraging steel TM210A was 0.69 .
\end{abstract}

Keywords: fatigue; ultra-high strength steel; TM210A; notch

\section{Introduction}

In order to meet the needs of high weight loads, high-transmission ratio, long life, weight and volume limits of important bearing units such as the leading edge flaps of a certain aircraft, material must have performance qualities such as high strength $\left(\sigma_{\mathrm{b}} \geq 2058 \mathrm{MPa}, \sigma_{0.2} \geq 1960 \mathrm{MPa}\right)$, high plasticity $\left(\delta_{5} \geq 7.5 \%, \psi \geq 45 \%\right)$, high toughness $\left(\alpha_{\mathrm{k}} \geq 39.2 \mathrm{~J} / \mathrm{cm}^{2}, \mathrm{~K}_{\mathrm{IC}} \geq 62 \mathrm{MPa} \cdot \mathrm{m}^{1 / 2}\right)$, high hardness $($ HRC $\geq 51)$ and high fatigue strength $\left(\sigma_{-1} \geq 680 \mathrm{MPa}\left(3 \times 10^{6}\right)\right)$. In the past many materials have been unable to meet these requirements. Recently, a new ultra-high strength maraging steel TM210A has been developed based on the design of the $18 \mathrm{Ni}$ maraging steel. The maraging steels are based on the iron-nickel-cobalt-molybdenum system that has emerged as an outstanding family of materials with exceptional combinations of characteristics. They are applied particulary in automotive, aerospace, nuclear, gear, bearing and other industries [1]. These grades generally contain $18 \mathrm{wt} \%$ nickel and are commonly designated as $18 \mathrm{Nixxxx}$, where $\mathrm{xxxx}$ is the nominal strength value attained by final heat treatment. Their outstanding attributes include ultra-high strength coupled with high fracture toughness, and excellent formability under hot and cold working conditions. The material is commercially available in different strength ranges from $1400 \mathrm{MPa}$ to $2400 \mathrm{MPa}$ [2]. The materials are low-carbon, and the chemical composition is: $\mathrm{C} \leq 0.03 \%, \mathrm{~S} \leq 0.01 \%, \mathrm{P} \leq 0.01 \%, \mathrm{Ni1} 18.5 \%, \mathrm{Co} 7.5 \%-9.5 \%$, $\mathrm{Mo} 3.25 \%-4.8 \%, \mathrm{Ti} \geq 0.2 \%, \mathrm{Al} \geq 0.1 \%$, and others $\mathrm{B}, \mathrm{Zr}, \mathrm{Ca}[3,4]$. 
At present, the material TM210A has been widely used in multi-type aircraft drive devices, such as gears, shafts, splines and other important bearing structures. These structural parts are unavoidably subjected to alternating loads during aircraft service. Fatigue damage is the main cause of failure of the important structural parts in the aircraft. Statistics show that most of the service failures of aircraft components occur in the form of fatigue damage, which amounts to about $60 \%$ of total failures [5].Serious air craft flight accidents involving fatigue-related causes are still occurring at about 100 times per year globally [6].

In this paper, rotating bending fatigue tests were carried out using the ultra-high strength maraging steel TM210Ain order to investigate the fatigue strength of the smooth specimen and the notched specimen, and to observe the fracture morphology. Finally, the fatigue notch sensitivity index was calculated.

\section{Experiment}

\subsection{Material and Specimen}

The experimental material was ultra-high strength steel TM210A. The chemical composition of TM210A is shown in Table 1. The material was solution-treated for $1 \mathrm{~h}$ at $820^{\circ} \mathrm{C}$ in a vacuum, followed by air-cooling and age-hardening for $4 \mathrm{~h}$ at $510 \pm 5{ }^{\circ} \mathrm{C}$ in a salt bath. This method enabled the determination of the plane-strain fracture toughness $\left(\mathrm{K}_{1 \mathrm{C}}\right)$ by increasing force of fatigue-precracked test specimens. Details of the test specimens and experimental procedures make reference to ISO 12737:2010(E).The mechanical properties of the TM210A are shown in Table 2. The microstructure of TM210A is the martensite shown in Figure 1. The shape and dimensions of the smooth specimen $\left(K_{t}=1\right)$ and notched specimen $\left(K_{t}=2\right)$ used in the fatigue experiment are shown in Figures 2 and 3, respectively.

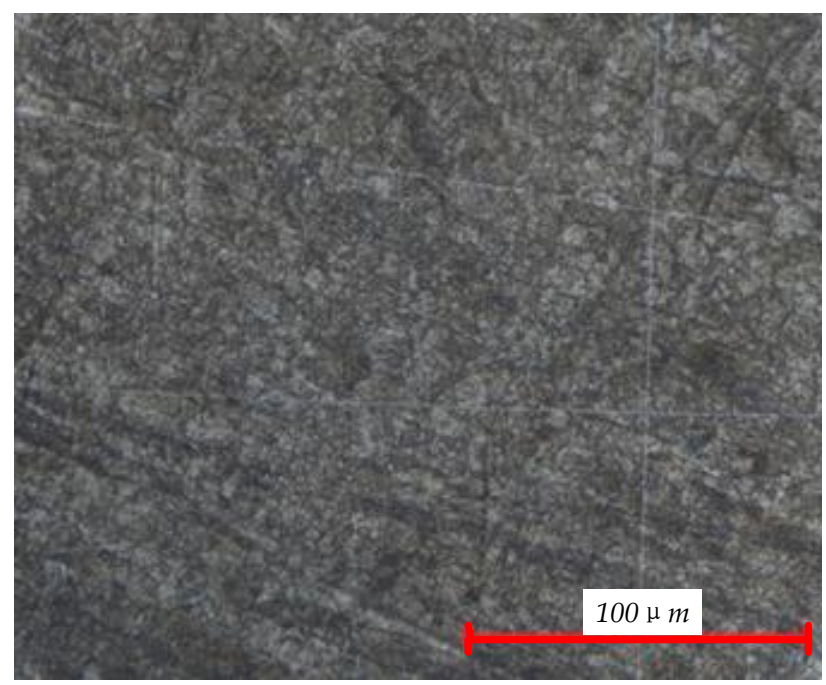

Figure 1. Microstructure of theTM210A.

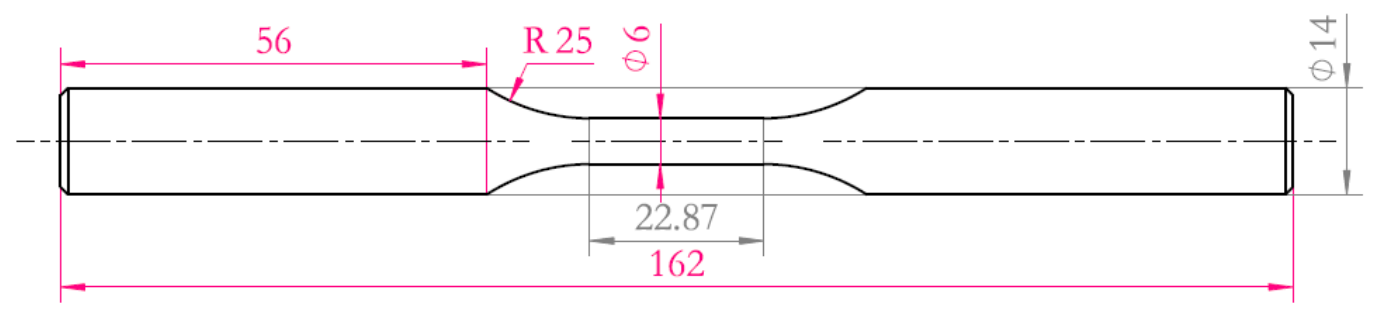

Figure 2. Schematic diagram of smooth round-bar fatigue specimen (unit: mm). 


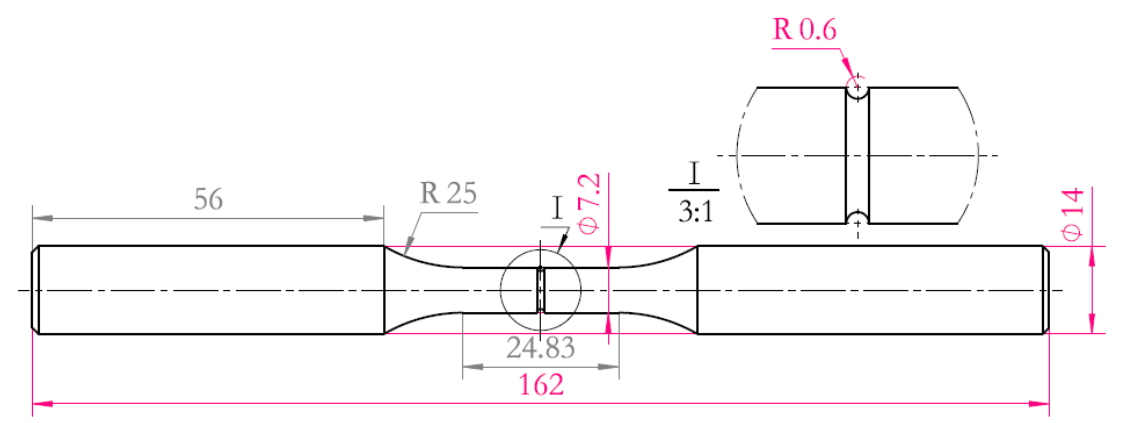

Figure 3. Schematic diagram of notched round-bar fatigue specimen (unit: $\mathrm{mm}$ ).

Table 1. Chemical composition of the TM210A (wt \%).

\begin{tabular}{cccccccccc}
\hline $\mathbf{C}$ & $\mathbf{S i}$ & $\mathbf{M n}$ & $\mathbf{S}$ & $\mathbf{P}$ & $\mathbf{N i}$ & $\mathbf{C o}$ & $\mathbf{M o}$ & $\mathbf{T i}$ & $\mathbf{A l}$ \\
\hline 0.003 & 0.09 & 0.09 & 0.005 & 0.004 & 17.70 & 10.32 & 4.30 & 0.97 & 0.10 \\
\hline
\end{tabular}

Table 2. Mechanical properties of the TM210A.

\begin{tabular}{cc}
\hline Mechanical Property & \\
\hline Tensile strength $\sigma_{\mathrm{b}}$ & $2125 \mathrm{MPa}$ \\
Yield strength $\sigma_{0.2}$ & $2065 \mathrm{MPa}$ \\
Elongation $\delta_{5}$ & $9.5 \%$ \\
Reduction of area $\psi$ & $60 \%$ \\
Impact toughness $\alpha_{\mathrm{k}}$ & $42 \mathrm{~J} / \mathrm{cm}^{2}$ \\
Fracture toughness $\mathrm{K}_{1 \mathrm{C}}$ & $65 \mathrm{Mpam}^{1 / 2}$ \\
Hardness & $55 \mathrm{HRC}$ \\
\hline
\end{tabular}

\subsection{Fatigue Experimental Method}

The constant amplitude rotating bending fatigue experimentswere performed in the PQ1-6 bending fatigue experimental machine. The working speed was constant at $5000 \mathrm{r} / \mathrm{min}$. The experimental environment was atmospheric temperature $\left(25 \pm 2{ }^{\circ} \mathrm{C}\right)$, humidity $(25 \%-40 \% \mathrm{RH})$, and the stress ratio was $R=-1$. The stress life $(\mathrm{S}-\mathrm{N})$ curve of the low /medium cycle fatigue regime was determined using the group method, and the fatigue limit at $1 \times 10^{7}$ cycles was determined using the staircase method. The fatigue tests were conducted at various stress levels in order to determine the mean S-N curve with a probability of failure of 50\%. The group method of the fatigue properties of metallic engineering materials was determined by testing a set of specimens at various stress levels to generate a fatigue life relationship as a function of stress. The results are expressed as an S-N curve that fits the experimental data, plotted in appropriate coordinates. The fatigue tests were conducted to generate strength data for a set of specimens in a sequential way using the staircase method. This starts the test at a first stress level that is preferably close to the estimated mean strength. It selects a stress step, preferably close to the standard deviation, by which to vary the stress level during the test. If no information is available about the standard deviation, a step of about $5 \%$ of the estimated mean fatigue strength may be used as the stress step. A first specimen, randomly chosen, is tested at the first stress level to see if it fails before the given number of cycles. For the next specimen, also randomly chosen, the stress level is increased by a step if the preceding specimen did not fail, and decreased by the same amount if it failed. Testing continues until all the specimens have been tested in this way. The fracture morphology of fatigue specimens was observed using a scanning electron microscope (SEM). 


\section{Results and Discussion}

\subsection{Fatigue Experimental Results}

The experiment was carried out from the high stress level to low stress level. The number of cycles to failure, abnormal phenomena, and specimen damage was recorded during the process. The experimental data for smooth and notched specimens of the TM210A are shown in Tables 3 and 4, respectively. From Table 3 to Table 4, the stress amplitudes of the smooth specimen fatigue test are shown at eight stress levels from $768 \mathrm{MPa}$ to $568 \mathrm{MPa}$; and the stress amplitudes of the notched specimen fatigue test at eight stress levels from $473 \mathrm{MPa}$ to $333 \mathrm{MPa}$. The average fatigue life at each stress level can be calculated, as shown in Tables 5 and 6 .

Table 3. Fatigue experimental data of the smooth specimens.

\begin{tabular}{ccccc}
\hline Specimen Number & Stress Amplitude & Fatigue Life & Comment & Crack Initiation Point \\
\hline 1 & $768 \mathrm{MPa}$ & 140,200 & Broken & At the specimen surface \\
2 & $768 \mathrm{MPa}$ & 203,200 & Broken & At the specimen surface \\
3 & $768 \mathrm{MPa}$ & 142,100 & Broken & At the specimen surface \\
4 & $728 \mathrm{MPa}$ & 152,700 & Broken & At the specimen surface \\
5 & $728 \mathrm{MPa}$ & 265,300 & Broken & At the specimen surface \\
6 & $728 \mathrm{MPa}$ & 130,500 & Broken & At the specimen surface \\
7 & $688 \mathrm{MPa}$ & 732,300 & Broken & At the specimen surface \\
8 & $688 \mathrm{MPa}$ & 189,400 & Broken & At the specimen surface \\
9 & $688 \mathrm{MPa}$ & 292,300 & Broken & At the specimen surface \\
10 & $648 \mathrm{MPa}$ & 534,300 & Broken & At the specimen surface \\
11 & $648 \mathrm{MPa}$ & 443,000 & Broken & At the specimen surface \\
12 & $648 \mathrm{MPa}$ & 678,600 & Broken & At the specimen surface \\
13 & $628 \mathrm{MPa}$ & $10,077,900$ & Run out & No \\
14 & $628 \mathrm{MPa}$ & $10,080,300$ & Run out & No \\
15 & $628 \mathrm{MPa}$ & $10,000,000$ & Run out & No \\
16 & $628 \mathrm{MPa}$ & 375,300 & Broken & At the specimen surface \\
17 & $608 \mathrm{MPa}$ & $1,174,400$ & Broken & At the specimen surface \\
18 & $608 \mathrm{MPa}$ & $5,132,900$ & Broken & At the specimen surface \\
19 & $608 \mathrm{MPa}$ & $3,684,100$ & Broken & At the specimen surface \\
20 & $588 \mathrm{MPa}$ & $10,000,000$ & Run out & No \\
21 & $588 \mathrm{MPa}$ & $10,078,200$ & Run out & No \\
22 & $588 \mathrm{MPa}$ & 372,100 & Broken & At the specimen surface \\
23 & $568 \mathrm{MPa}$ & $10,080,600$ & Run out & No \\
\hline
\end{tabular}

Table 4. Fatigue experimental data of the notched specimens.

\begin{tabular}{ccccc}
\hline Specimen Number & Stress Amplitude & Fatigue Life & Comment & Crack Initiation Point \\
\hline 1 & $473 \mathrm{MPa}$ & 91,300 & Broken & At the edge of the notch \\
2 & $473 \mathrm{MPa}$ & 70,400 & Broken & At the edge of the notch \\
3 & $473 \mathrm{MPa}$ & 86,900 & Broken & At the edge of the notch \\
4 & $453 \mathrm{MPa}$ & 91,300 & Broken & At the edge of the notch \\
5 & $453 \mathrm{MPa}$ & 70,400 & Broken & At the edge of the notch \\
6 & $453 \mathrm{MPa}$ & 86,900 & Broken & At the edge of the notch \\
7 & $413 \mathrm{MPa}$ & 241,600 & Broken & At the edge of the notch \\
8 & $413 \mathrm{MPa}$ & 252,600 & Broken & At the edge of the notch \\
9 & $413 \mathrm{MPa}$ & 563,700 & Broken & At the edge of the notch \\
10 & $393 \mathrm{MPa}$ & 485,500 & Broken & At the edge of the notch \\
11 & $373 \mathrm{MPa}$ & $1,967,700$ & Broken & At the edge of the notch \\
12 & $373 \mathrm{MPa}$ & $1,063,000$ & Broken & At the edge of the notch \\
13 & $373 \mathrm{MPa}$ & $2,702,000$ & Broken & At the edge of the notch \\
14 & $373 \mathrm{MPa}$ & 679,000 & Broken & At the edge of the notch \\
15 & $373 \mathrm{MPa}$ & $10,070,000$ & Run out & No \\
16 & $353 \mathrm{MPa}$ & $10,068,700$ & Run out & No \\
\hline
\end{tabular}


Table 4. Cont.

\begin{tabular}{ccccc}
\hline Specimen Number & Stress Amplitude & Fatigue Life & Comment & Crack Initiation Point \\
\hline 17 & $353 \mathrm{MPa}$ & $10,068,900$ & Run out & No \\
18 & $353 \mathrm{MPa}$ & $10,068,000$ & Run out & No \\
19 & $353 \mathrm{MPa}$ & $2,491,300$ & Broken & At the edge of the notch \\
20 & $353 \mathrm{MPa}$ & $10,072,700$ & Run out & No \\
21 & $353 \mathrm{MPa}$ & 715,300 & Broken & At the edge of the notch \\
22 & $333 \mathrm{MPa}$ & $10,074,000$ & Run out & No \\
23 & $333 \mathrm{MPa}$ & $10,074,800$ & Run out & No \\
\hline
\end{tabular}

Table 5. Fatigue life of the smooth specimens with 50\% survival rate.

\begin{tabular}{ccccc}
\hline$S_{\max } / \mathrm{MPa}$ & 768 & 728 & 688 & 615 \\
\hline$N_{50} /$ cycle & 159,368 & 174,221 & 343,558 & $10^{7}$ \\
\hline
\end{tabular}

Table 6. Fatigue life of the notched specimens with $50 \%$ survival rate.

\begin{tabular}{ccccc}
\hline$S_{\max } / \mathrm{MPa}$ & 473 & 453 & 413 & 363 \\
\hline$N_{50} /$ cycle & 82,357 & 173,021 & 325,237 & $10^{7}$ \\
\hline
\end{tabular}

\section{2. $S-N$ Curves}

The S-N curve is a basic curve for characterizing the fatigue properties of the material. According to the experimental data from Tables 3-6, the S-N curves of the smooth specimen and the notched specimen can be fitted. The S-N curve has a variety of forms of expression. The three-parameter S-N curve model can be used to describe the stress-life relationship of the long-life region. This study selected the classical three-parameter power function S-N curve model [7].

$$
N\left(S_{\max }-S_{0}\right)^{H}=C
$$

where $S_{\max }$ is the maximum stress, $N$ is the fatigue life, $S_{0}$ is the theoretical fatigue limit, $H$ and $C$ are the material constant. A double weighted least square method is used for fitting.

From the data in Tables 3 and 5, the parameters of the smooth specimen were obtained, $S_{0}=613.1649 \mathrm{MPa}, \mathrm{H}=0.9665, \mathrm{C}=1.9333 \times 10^{7}$, and the $\mathrm{S}-\mathrm{N}$ curve equation of the smooth specimen was obtained

$$
N\left(S_{\max }-613.1649\right)^{0.9665}=1.9333 \times 10^{7}
$$

According to the fitting equation, we can draw the S-N curve of the smooth specimens of the ultra-high strength maraging steel TM210A with a 50\% survival rate, as shown in Figure 4 . It can be seen that the fatigue limit of the smooth specimen was not more than $615 \mathrm{MPa}$.

From the data in Tables 4 and 6 , the parameters of the notched specimen were obtained, $S_{0}=350.8066 \mathrm{MPa}, \mathrm{H}=2.0649, \mathrm{C}=1.7488 \times 10^{7}$, and the $\mathrm{S}-\mathrm{N}$ curve equation of the notched specimen was obtained

$$
N\left(S_{\max }-350.8066\right)^{2.0649}=1.7488 \times 10^{7}
$$

According to the fitting equation, we can draw the S-N curve of the notched specimens of the ultra-high strength maraging steel TM210A with a 50\% survival rate, as shown in Figure 5. It can be seen that the fatigue limit of the notched specimen was not more than $365 \mathrm{MPa}$. 


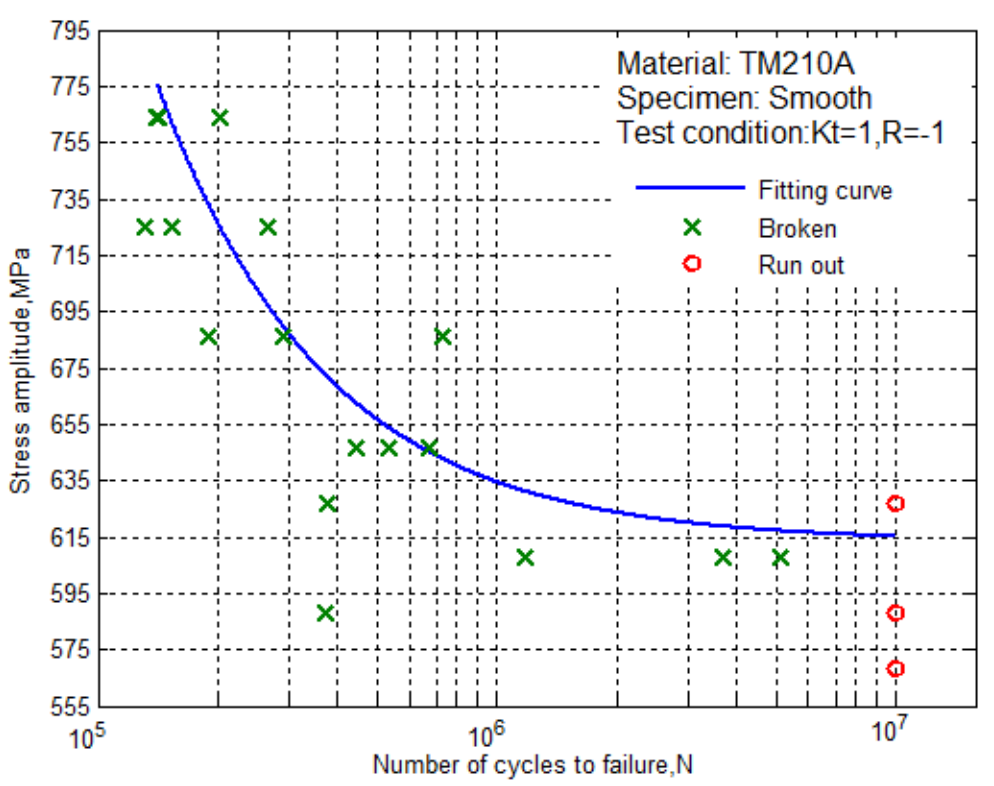

Figure 4 . The S-N curve for the smooth specimens with 50\% survival rate.

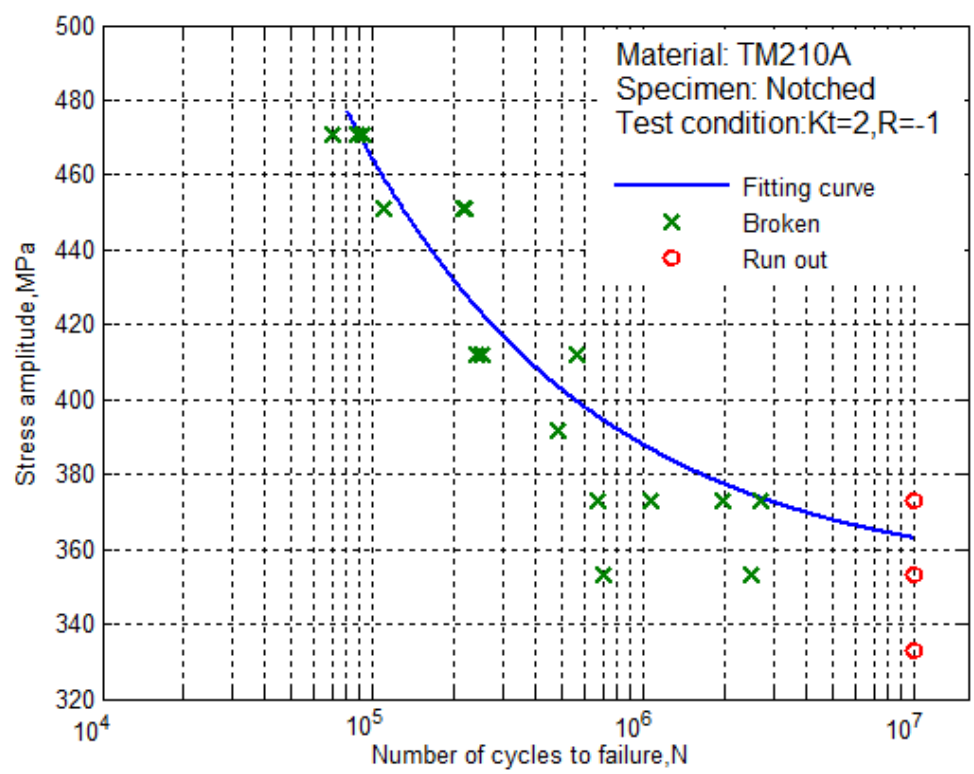

Figure 5. The S-N curve for the notched specimens with 50\% survival rate.

From Figure 4 to Figure 5, it can be seen that the S-N curves of the smooth specimens and the notched specimens of the ultra-high strength maraging steel TM210A decreased with the decrease of the stress level, and the fatigue life was prolonged. The fatigue stress-life data contained two parts. Part 1: the data of the test was from initiation to before the fatigue limit, which corresponded to the fracture of the specimen due to the crack initiation-expansion (cross symbols). Part 2: the data of the test was at lower stress levels, in which the specimen did not break (circular symbols).

For a more intuitive process, Figures 6 and 7 show the fatigue lift graphs for smooth and notched specimens at $1 \times 10^{7}$ cycles, respectively. Only five stress levels were considered in the analysis of the smooth specimen, as shown in Figure 6, where the beginning stress was 628MPa, the step stress was $20 \mathrm{MPa}$, and the number of the effective specimen was 14 . Only four stress levels were considered in the analysis of the notched specimen, as shown in Figure 7, where the stress began at $373 \mathrm{MPa}$, the step stress was $20 \mathrm{MPa}$, and the number of the effective specimen was 13 . 


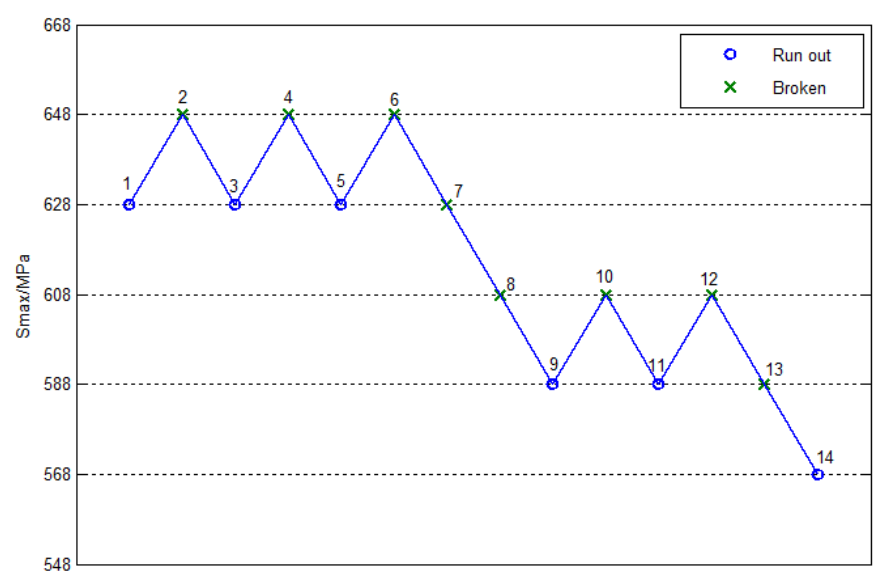

Figure 6. The staircase figure of smooth specimens.

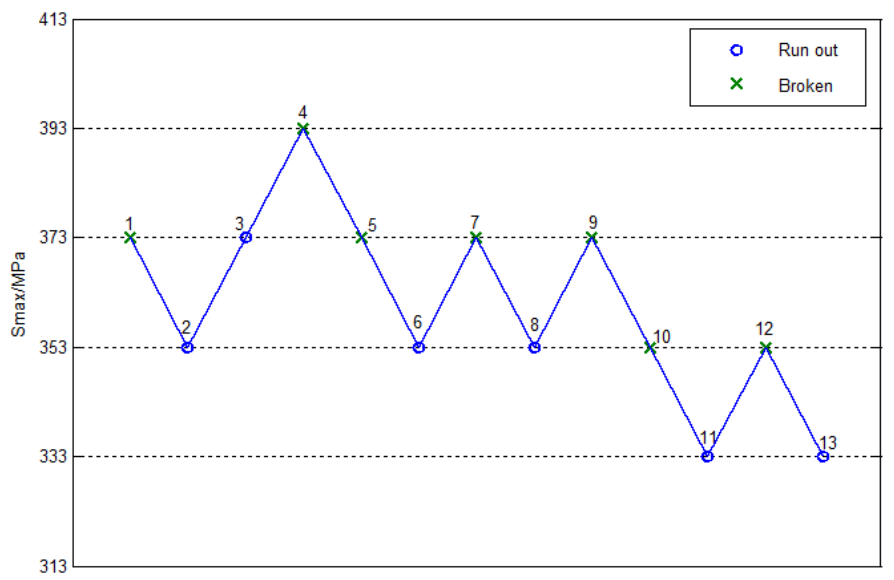

Figure 7. The staircase figure of notched specimens.

According to the statistical theory

$$
\sigma_{-1}=\frac{1}{k} \sum_{i=1}^{k} \sigma_{i}=\frac{1}{n} \sum_{j=1}^{l} v_{j} \sigma_{j}
$$

where $\sigma_{-1}$ is the mean fatigue limit, $k$ is the number of matched pairs, $n$ is the number of effective specimens, $l$ is the number of the stress levels, $\sigma_{i}$ is the $i$-th pair fatigue limit in the matched pair, $\sigma_{j}$ is the $j$-th level stress value of the stress levels, and $v_{j}$ is the number of the effective specimen in the $j$-th level stress level, whether the specimen is broken or not.

Therefore, the fatigue limit of the smooth specimen was 615MPa.The ratio of the fatigue limit to tensile strength was 0.29. The fatigue limit of the notched specimen was 363MPa. Besides this, the fatigue limit of the notched specimen was reduced by about $41 \%$ compared with the smooth specimen.

\subsection{Fractography}

The fracture micrographs of the smooth specimens and notched specimens of the ultra-high strength maraging steel TM210A were observed by scanning electron microscopy, as shown in Figures 8 and 9 , respectively. It can be seen that the fractures were composed of the crack initiation area, the crack propagation area, and the instantaneous fracture area, whether it was a smooth or notched specimen.

As shown in Figure 8, the crack initiation of the smooth specimen was at the surface of the specimen. In the vicinity of the crack initiation, the crack occurred in a quasi-cleavable way, with a 
distinct river pattern. The crack propagation area had obvious fatigue striations, and there were some relatively large step shapes. The instantaneous fracture area was a rough dimple.

As shown in Figure 9, the crack initiation of the notched specimen was at the front end of the annular circumference notch with a large stress concentration, in a distinct river pattern. The crack propagation area had obvious fatigue striations, and there were obvious tear edges. The instantaneous fracture area was a rough dimple.

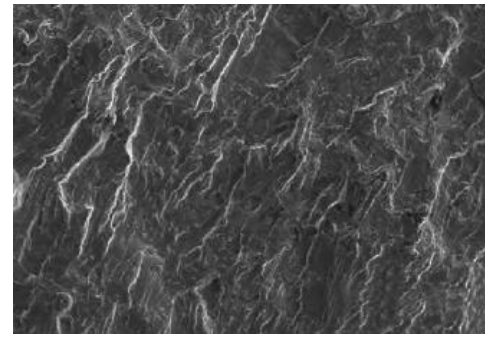

(a)

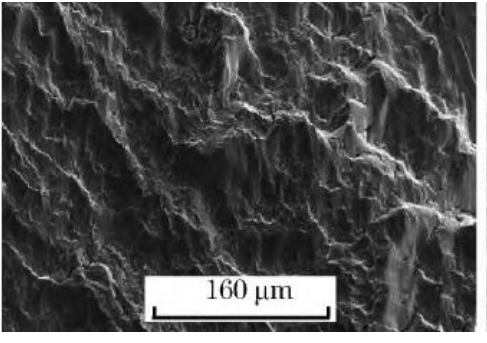

(b)

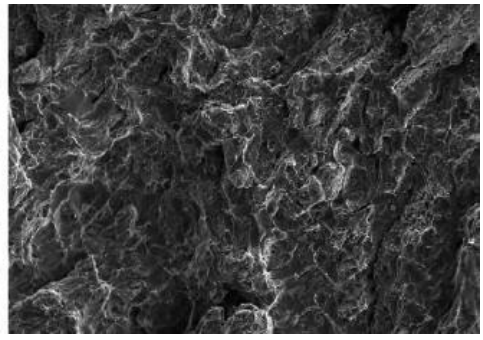

(c)

Figure 8. Microstructures of fractures of the smooth specimen: (a) Crack initiation; (b) Crack propagation; (c) Instantaneous fracture

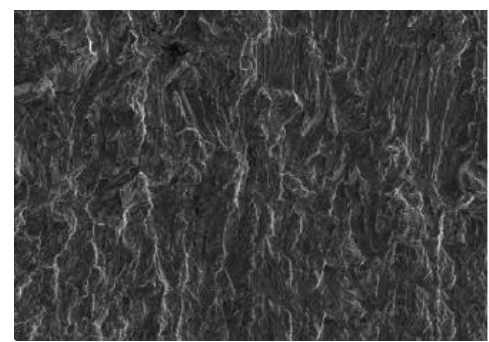

(a)

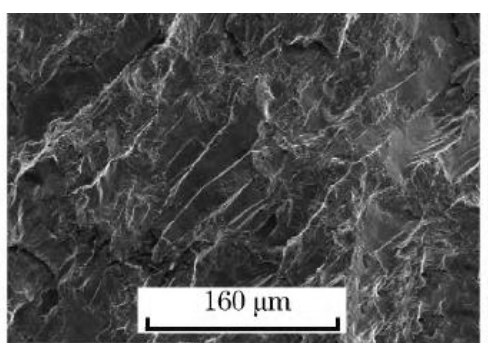

(b)

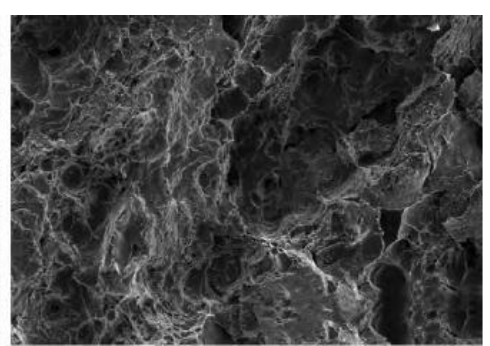

(c)

Figure 9. Microstructures of fractures of the notched specimen: (a) Crack initiation; (b) Crack propagation; (c) Instantaneous fracture

\subsection{Fatigue Notch Sensitivity Index}

The theoretical elastic stress concentration factor $K_{t}$ relates the local stress ahead of the notch tip to far-field loading, and is defined as the ratio of the maximum local stress $\sigma_{\max }$ to the nominal stress S. Under fatigue loading conditions, the elastic stress concentration factor is replaced by the so-called fatigue notch factor:

$$
K_{f}=\frac{\text { unnotched bar endurance limit }}{\text { notched bar endurance limit }}
$$

In general, fatigue experiments suggest that notches produce a less stress-concentrating effect than predicted by theoretical elastic analysis, such that we find $K_{f}<K_{t} ; K_{f} \rightarrow K_{t}$ for large notch-root radii and for higher strength materials. The degree of agreement between theoretical predictions of elastic stress concentration and actual effects is often measured by the so-called notch sensitivity index, which is defined as [8]

$$
q_{f}=\frac{K_{f}-1}{K_{t}-1} \quad\left(0 \leq q_{f} \leq 1\right)
$$

The fatigue limits of the smooth specimen and the notched specimen of the TM210A were $615 \mathrm{MPa}$ and $363 \mathrm{MPa}$, respectively. The theoretical elastic stress concentration factor $K_{t}$ was 2 , and, therefore, the fatigue notch sensitivity index $q_{f}$ was 0.69 . 


\section{Conclusions}

In order to investigate the fatigue strength and the facture mode of the ultra-high strength maraging steel TM210A, rotating bending fatigue tests were carried out using a smooth specimen and a notched specimen. The main results obtained were as follows:

(1) The mean fatigue $\mathrm{S}-\mathrm{N}$ curve and the mean fatigue limit of the smooth specimen and the notched specimen of the ultra-high strength maraging steel TM210Awere obtained in experiments. The fatigue limits of the smooth specimen and notched specimen were $615 \mathrm{MPa}$ and $363 \mathrm{MPa}$, respectively. The ratio of the fatigue limit to tensile strength was 0.29 . The fatigue limit of the notched specimen was reduced by about $41 \%$ compared to the smooth specimen, which indicated that the notch had a great impact on the fatigue properties of materials.

(2) The fracture micrographs of the smooth specimens and notched specimens of the ultra-high strength maraging steel TM210A were composed of a crack initiation area, a crack propagation area, and an instantaneous fracture area. The smooth specimen crack initiated at the specimen surface, and the notched specimen crack initiated at the edge of the notch with a large stress concentration.

(3) The fatigue notch sensitivity index of the ultra-high strength maraging steel TM210A was 0.69.

Acknowledgments: This research was sponsored by Qing'an Group Corporation Limited.

Author Contributions: Guang-qiang Yin was responsible for drafting the manuscript, conceived and designed the experiments, andexecuted the experimental tests. Xia Kang assisted Guang-qiang Yin with processing the data for the statistical analysis. Gui-ping Zhao was responsible for overseeing the project and finalizing the writing of the manuscript.

Conflicts of Interest: The authors declare no conflict of interest.

\section{References}

1. Wei, S. Steels; Springer: London, UK, 2013; pp. 144-147.

2. Rao, M.N. Progress in understanding the metallurgy of $18 \%$ nickel maraging steels. Int. J. Mater. Res. 2006, 97, 1594-1607. [CrossRef]

3. Hoseini, S.R.E.; Arabi, H.; Razavizadeh, H. Improvement in mechanical properties of C300 maraging steel by application of VAR process. Vacuum 2008, 82, 521-528. [CrossRef]

4. Novotny, P.M.; Maurer, G.E. Ultra-high-strength steels vs. titanium alloys. Adv. Mater. Process. 2007, 165, $37-40$.

5. Bhaumik, S.K.; Sujata, M.; Venkataswamy, M.A. Fatigue failure of aircraft components. Eng. Fail. Anal. 2008, 15, 675-694. [CrossRef]

6. Campbell, G.S.; Lahey, R. A survey of serious aircraft accidents involving fatigue fracture. Int. J. Fatigue 1984, 6, 25-30. [CrossRef]

7. Little, R.E.; Jebe, E.H. Statistical Design of Fatigue Experiments; Applied Science Publishers Ltd.: London, UK, 1975.

8. Suresh, S. Fatigue of Materials, 2nd ed.; Cambridge University Press: Cambridge, UK, 1998; pp. 242-243.

(C) 2017 by the authors. Licensee MDPI, Basel, Switzerland. This article is an open access article distributed under the terms and conditions of the Creative Commons Attribution (CC BY) license (http:/ / creativecommons.org/licenses/by/4.0/). 